\title{
Unregulated serving sizes on the Canadian nutrition facts table - an invitation for manufacturer manipulations
}

\author{
Jessica Yin Man Chan ${ }^{1,2}$, Mary J. Scourboutakos ${ }^{1}$ and Mary R. L'Abbé ${ }^{*}$
}

\begin{abstract}
Background: Serving sizes on the Nutrition Facts table (NFt) on Canadian packaged foods have traditionally been unregulated and non-standardized. The federal government recently passed legislation to regulate the serving sizes listed on the NFt. The objective of this study was to compare the serving sizes on food product NFts to the recommendations in the 2003 Nutrition Labelling regulation (Schedule M) reference amounts, the Canadian Food Inspection Agency (CFIA) ranges, and Canada's Food Guide recommendations. An additional objective was to determine if food and beverage products that report smaller serving sizes have a higher calorie density, compared to similar products with a larger serving size.
\end{abstract}

Methods: Data for 10,487 products were retrieved from the 2010 Food Label Information Program (FLIP) database and categorized according to Schedule M categories. Correlations between calorie density and manufacturer stated serving size were tested and the proportion of products meeting recommendations were tabulated.

Results: $35 \%$ of products had serving sizes on the NFt that were smaller than the Schedule M reference amount and $23 \%$ exceeded the reference amount. $86 \%$ of products fell within the CFIA's recommended serving size ranges;

however, $70 \%$ were within the lower-half of the range. Several bread and juice categories exceeded CFG's recommendations, while several dairy product categories were smaller than the recommendations. Of the 50 Schedule M sub-categories analyzed, 31 (62\%) exhibited a negative correlation between serving size and calorie density.

Conclusion: While most products fell within the CFIA's recommended serving size ranges, there was a tendency for products with a higher calorie density to list smaller serving sizes.

Keywords: Nutrition facts table, Serving size, Standardized serving size, Reference amount, Nutrition labels, Nutrition labelling, Calorie density, Public health, Schedule M, Health Canada

\section{Background}

In recent years there has been a substantial increase in the prevalence of obesity in Canada. Presently $62.1 \%$ of Canadian adults are overweight, and $25 \%$ are obese [1]. The rise in obesity has been paralleled by the consumption of excess calories, partially due to increased portion sizes [2].

The Nutrition Facts table (NFt) is mandated to appear on nearly all packaged foods sold in Canada [3]. The serving size stated on the Nutrition Facts table determine the nutrient levels that will be reported on that label (for

\footnotetext{
*Correspondence: mary.labbe@utoronto.ca

${ }^{1}$ Faculty of Medicine, Department of Nutritional Sciences, University of Toronto,

Fitzgerald Building, 150 College St., Rm 315, Toronto, ON M1S 3E2, Canada

Full list of author information is available at the end of the article
}

example, a smaller serving size reports fewer calories, while a larger serving size reports more calories). Traditionally, the serving sizes stated on the NFt on packaged foods sold in Canada were not standardized and could be determined by manufacturers, unlike in the United States, where the FDA regulates serving sizes [4]. Therefore, food companies could decide the serving size, and thus the number of calories a consumers sees when looking at a Nutrition Facts table. In other countries and jurisdictions, such as the EU, UK, and Australia, nutrition information is listed per $100 \mathrm{~g}$ to enable comparisons among similar products $[5,6]$. The Canadian NFt does not feature nutrition information per $100 \mathrm{~g}$. 
Research has demonstrated that the reported serving sizes on NFts are often smaller than the portions typically consumed [7]. This suggests that food companies may be intentionally trying to reduce the reported calories on the nutrition label by using smaller serving sizes [8]. Additionally, research has demonstrated that using different serving sizes on the NFts of similar products, confuses consumers and makes comparisons among similar foods difficult. As a result, consumers have difficulty determining the energy content per serving and per package, and cannot accurately calculate calorie content when there is more than one serving per container [9]. Furthermore, anticipated guilt from consumption, purchase intentions, and choice behaviour, can be influenced by serving size manipulations, and may disproportionately influence weight-conscious consumers who are concerned about calories, but not serving size [8].

In Canada, two important government bodies i) Health Canada and ii) the Canadian Food Inspection Agency (CFIA) are responsible for Canadian food labelling regulations and public governance. Health Canada is responsible for administering the provisions of the Food and Drugs Act (FDR) that relate to public health, safety and nutrition [10]. Whereas the CFIA provides all federal inspection services related to food and enforces the food safety and nutritional quality standards established by Health Canada, i.e. responsible for the administration and enforcement of the Consumer Packaging and Labelling Act related to food [11]. The CFIA regulates the consistency, completeness and accuracy of the labelling and packaging of consumer goods. These regulations are intended to provide a fair and competitive marketplace by prohibiting deceptive labelling or advertising practices.

Reference amounts for the serving size on Nutrition Facts tables have been established by Health Canada and are set out in Schedule $\mathrm{M}$ of the Food and Drug Regulations (FDR) (B.01.001) [12]. Traditionally, these reference amounts were mandatory only as the basis for calculating the compositional criteria that manufacturers must meet for nutrient content claims and health claims [3]. For products without any nutrient content claims and health claims, the CFIA recommends manufacturers follow the range of serving sizes set in the CFIA Guide to Food Labelling and Advertising (CFIA guide), however, these ranges are not mandatory and only serves as a reference for manufacturers to stay within the recommended ranges [13]. In comparison, in the United States, standardized serving sizes used on the Nutrition Facts table have been regulated by the Food and Drug Administration (FDA) for more than 20 years and are required to conform to the Reference Amount Customarily Consumed (RACC) defined in section 101.12(b) of the food labelling regulations [14].

It was suggested that standardizing the serving sizes reported on the Canadian NFt could be an important policy intervention to help consumers make informed healthy food choices [3]. In December 2016, changes were made to the Food and Drug regulations in Canada that now require food manufacturers to use similar serving sizes for similar products $[10,15]$. However, this new regulations will not be fully implemented until 2021. By modifying serving sizes to be more consistent and listing realistic measures, it is expected that Canadians will be more easily able to compare similar foods and make it easier to understand how many calories and nutrients they are consuming. This study was initiated before the new legislation was announced. Therefore, the objective of this study was to compare the serving sizes on food product NFTs to the recommendations in the 2003 Nutrition Labelling regulation (Schedule $M$ ) reference amounts, the CFIA recommended ranges, and Canada's Food Guide (CFG) recommendations. The goal was to determine the number of foods that currently adhere to the voluntary Canadian FDR Schedule $M$ serving size recommendations (reference amount) as well as the CFIA recommended serving ranges. Comparing serving sizes on food product NFTs to the CFG recommendations is needed to investigate the consistency between the serving sizes recommended in regulatory documents versus consumer education tools for healthy eating. Our second aim was to determine if food and beverage products that have a higher calorie density report a smaller serving size on the NFt, when compared to similar products with a larger serving size. Overall, the aim is for these results to shed light on the potential benefits of the new nutrition labelling changes, to be implemented on Canada, over the next five years.

\section{Methods}

\section{Data collection}

This was a cross-sectional analyses of the serving size and calories listed on the NFt on 10,487 packaged foods from Canadian grocery stores. Canadian food package label information, as reported on the NFt, was retrieved from the 2010 Food Label Information Program (FLIP) database at the University of Toronto [16]. All data were collected between March 2010 and April 2011 from outlets of the four largest grocery chains in Canada (Loblaws, Metro and Sobeys in Ontario) and one major western Canadian grocery retailer (Safeway, in Alberta). These chains represented approximately $75 \%$ of the market share of grocery food products sold in Canada; therefore, most national and private label branded food products were collected. A total of 10,487 unique food products were in the FLIP database. Additional details concerning the construction of the FLIP 2010 database can be found elsewhere [16].

\section{Food classifications and reference serving sizes}

All food items were categorized according to the Schedule $\mathrm{M}$ categories and sub-categories, as described in the 
Canadian Food Inspection Agency (CFIA) guide. Schedule $\mathrm{M}$ is a component of the Canadian Food and Drug Nutrition Labelling Regulations [B.01.001] and lists serving size reference amounts and recommended serving size ranges for 22 categories and 153 subcategories [3]. The reference amount is a specific regulated quantity of food (measured in grams) and it is meant to represent the portion that would typically be eaten by an individual at one sitting, but is not required to be used by manufacturers on the NFt (Additional file 1).

The CFIA guide provides a range of suggested serving sizes within each of the Schedule $M$ subcategories to guide manufacturer determined serving sizes [3]. The ranges are meant to give manufacturers flexibility when determining the appropriate serving size to disclose on a product's NFt, however, manufacturers are not required to follow these serving size reference amounts. Use of reference amounts are only mandatory as the basis for determining eligibility of a food to carry nutrient content claims and health claims.

In order to compare manufacturer stated serving sizes to a standardized serving size, schedule $M$ reference amounts were assigned to each food product based on the sub-category that best matched the product's description. To ensure that food items were categorized consistently, data were checked by a second independent reviewer. In any case of discrepancies, the CFIA was contacted to verify categorizations. A description of the Schedule M subcategories and the food products within each subcategory can be found in Additional file 1 .

\section{Inclusion and exclusion criteria}

Of the 153 schedule $\mathrm{M}$ sub-categories, all sub-categories with at least 50 unique food items were included in this analysis leaving a total of 7494 foods for analysis. For categories with less than 50 food items, sample size might be too small to reflect all existing products across the country. Thus, excluding those categories might help reduce selection bias.

Data analysis Descriptive statistics were calculated for the serving size and calorie content listed on the NFt (according to the manufacturer stated serving size). The proportion of products with serving sizes that were less than, equal to, or greater than the reference amount listed in Schedule $M$ were tabulated. The proportions of products with serving sizes below, within, and above the range of recommended serving sizes set out in the CFIA Guide were also tabulated. Additionally, when a product's serving size was within the CFIA range of recommended serving sizes, the proportion of products in the lower half and upper half of the range was calculated.

Each product's calorie density (calculated as calories per $100 \mathrm{~g}$ and calories per reference amount) were calculated.
For each product, scatter plots for the calories per reference amount in comparison to the food product's stated serving size were created to study the association between calorie density and serving size. Correlations between calorie density and serving size were tested using Pearson correlation.

The sign test was used to detect differences between the calories per serving and calories per reference amount, within each food category. All statistical analyses were performed using Statistica, version 10 (Tulsa, OK). A $p$-value $<0.05$ was considered significant.

\section{Results}

Fifty schedule M sub-categories containing 7494 food products were analysed. The 50 sub-categories included in this study are listed in Table 1.

\section{Comparison of serving sizes in relation to schedule $\mathbf{M}$ reference amounts}

Table 1 compares the manufacturer stated serving sizes reported on the NFt with the Schedule M reference amount and CFIA recommended serving size ranges. 35\% of products had serving sizes that were lower than the reference amount in schedule $M, 42 \%$ of products had serving sizes that were consistent with the reference amount, and $23 \%$ exceeded the reference amount. In nine categories, (representing 18\% of all categories) more than $70 \%$ of products had serving sizes that were smaller than the reference amount. The nine categories were 'French toast, pancakes, and waffles'; 'Pies, tarts, cobblers, turnovers'; 'Quark, fresh cheese and fresh dairy desserts'; 'Yogurt'; 'Dairy desserts, frozen'; 'Dressings for salad'; 'Marine and fresh water animals'; 'Fruit, fresh, canned or frozen' and 'Meat and poultry with sauce'. Furthermore, in an additional twelve categories, (representing 24\% of all categories) more than half of the products had serving sizes that were smaller than the reference amount.

\section{Comparison of serving sizes in relation to CFIA recommended serving size ranges}

When compared to the CFIA recommended serving size ranges, $10 \%$ of products had manufacturer stated serving sizes that were smaller than the recommended range, $86 \%$ were within the recommended range, and $4 \%$ were larger than the recommended range. However, among products whose serving size fell within the recommended range, 70\% fell within the lower-half of the recommended range, while $30 \%$ fell within the higher half of the recommended range.

\section{Comparison of serving sizes in relation to Canada's food guide}

Only a limited number of categories could be compared to the Canada Food Guide recommended serving sizes due to different food categorization systems. In addition, 


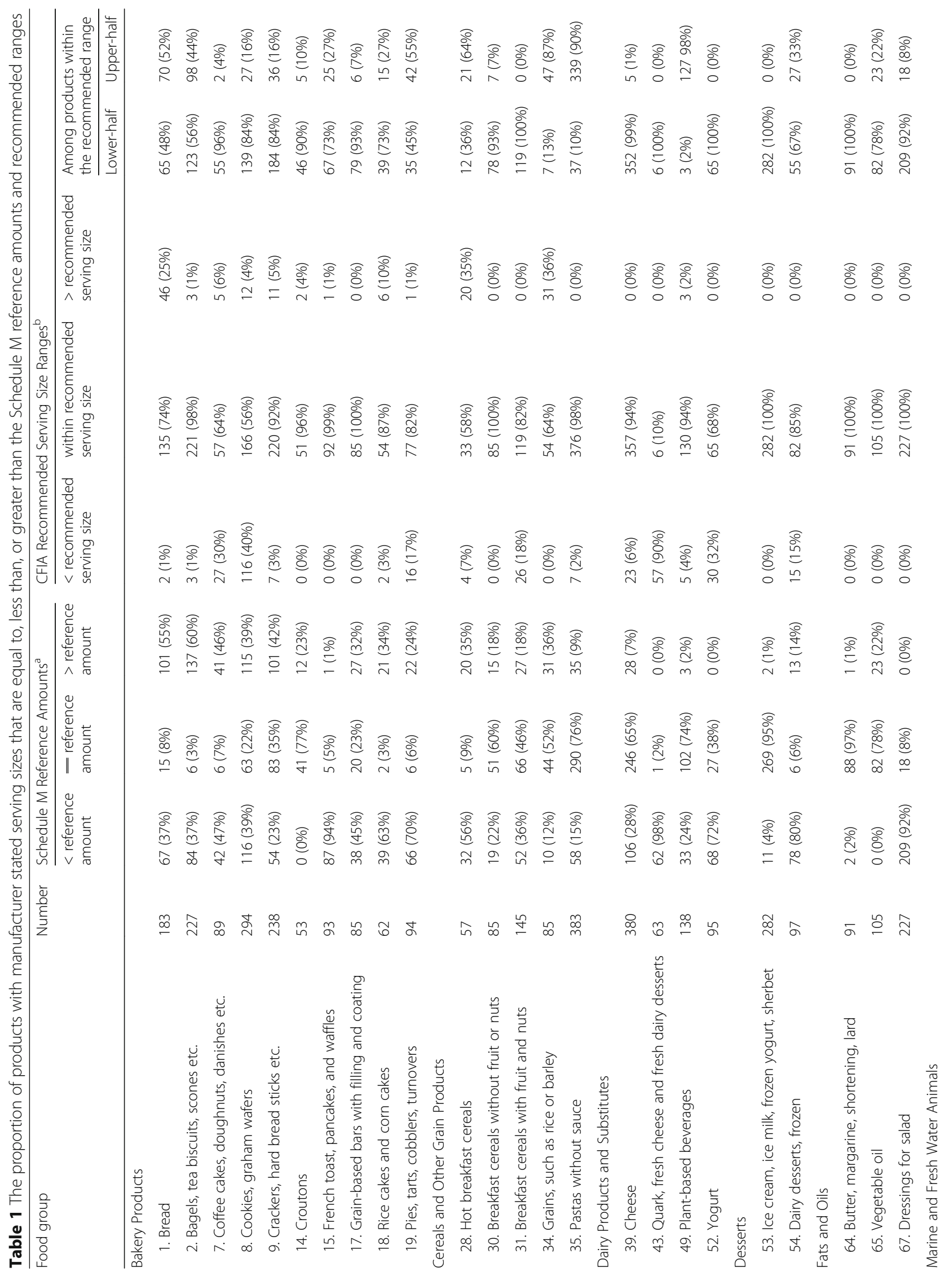




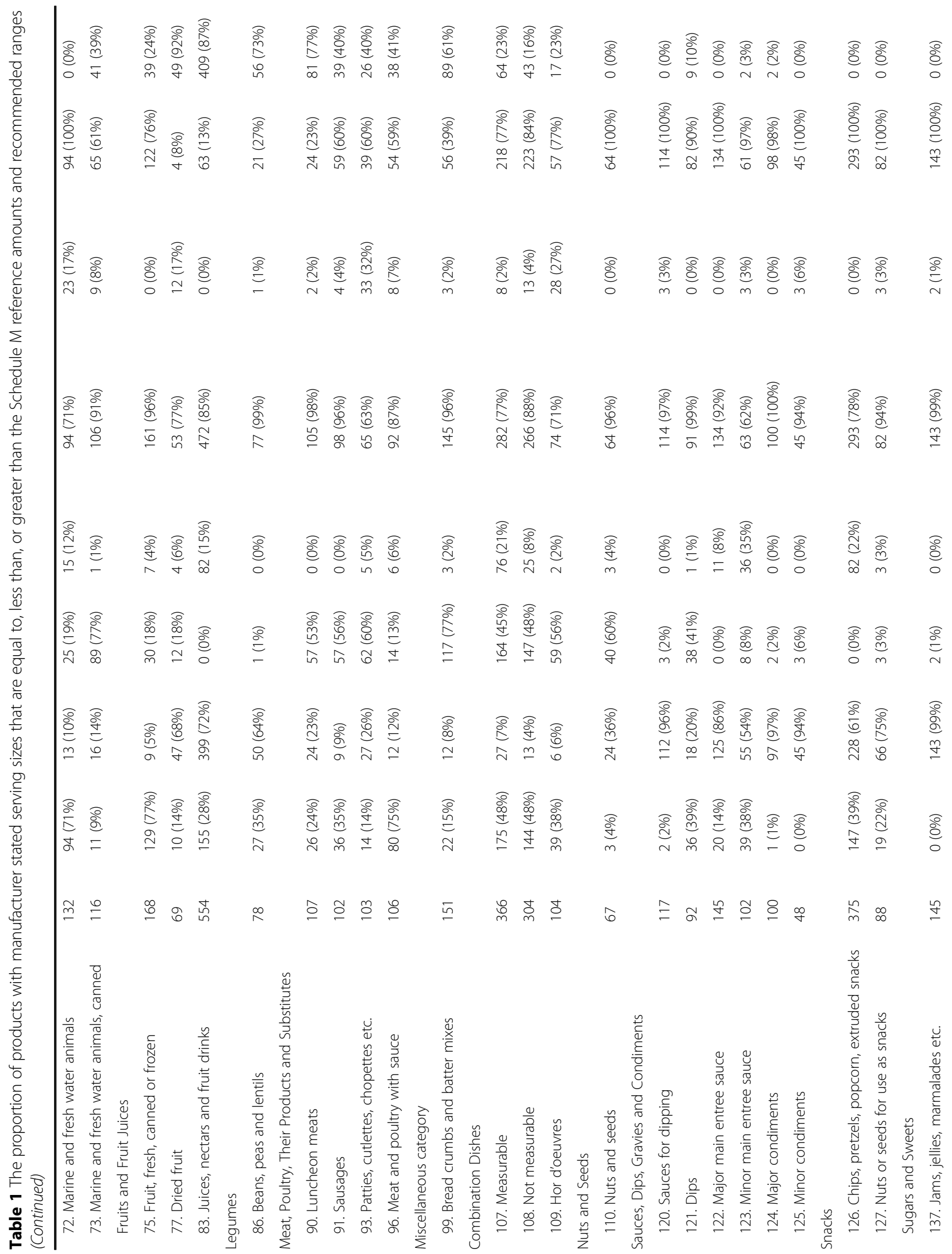




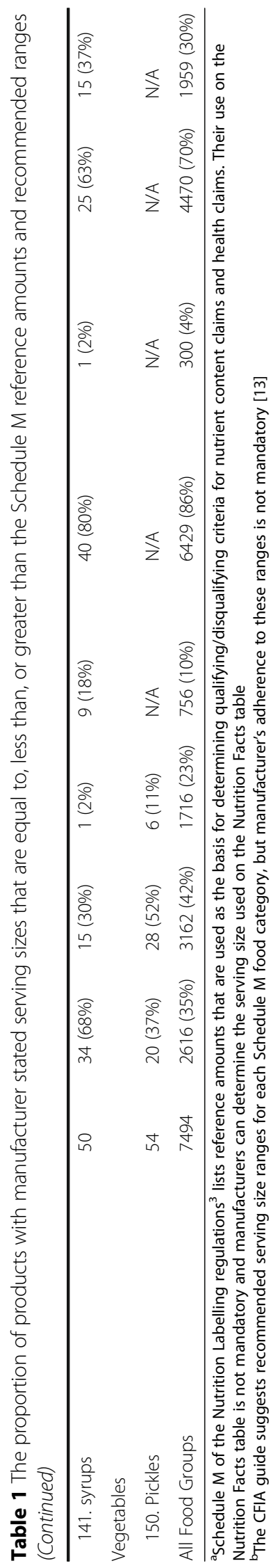


the recommended serving sizes in CFG were primarily based on cooked food portions, whereas the serving size on food product NFts were based on raw food portions, this further limited the number of categories that could be compared. In 'bread'; 'bagels, tea biscuits, scones'; and 'juices, nectars and fruit drinks', $80-90 \%$ of products had manufacturer stated serving sizes that were higher than those recommended by Canada's food guide. Meanwhile in 'cheese' and 'quark, fresh cheese and fresh dairy desserts', $90-99 \%$ of products had manufacturer stated serving sizes that were smaller than the Canada Food Guide Recommended Serving Sizes.

\section{Comparison of calorie content currently listed on the NFt versus the reference amount}

Table 2 shows the median calories in each category as currently listed on the NFt in comparison to the amount that would be listed if manufacturers were required to use the reference amounts for standardized serving sizes. In 21 of the 50 categories analysed (42\% of categories), the median amount of calories reported on the NFt (for that category) was significantly lower than the amount that would be stated if manufacturers were required to adhere to the reference amount serving sizes. In contrast, there were only seven categories ( $14 \%$ of categories) where the median calories based on the manufacturer stated serving size was significantly higher than the amount of calories that would be stated if reference amounts were required. Notably 'Quark, fresh cheese and fresh dairy desserts'; 'Dressings for salad' and 'Syrups' had the highest differences in calorie levels which would be stated 317\%, 200\% and 183\% larger, respectively, if the standardized reference amounts were used on the NFt. Categories showing a moderately low manufacturer stated serving size ( $20 \%$ to $30 \%$, when compared to schedule $M$ reference amounts) included: 'Yogurt'; 'Marine and fresh water animals'; 'Meat and poultry with sauce'; and 'Minor main entree with sauce'.

\section{Correlation between calorie density and serving size}

There was a significant negative correlation between serving size and calorie density in 31 categories $(62 \%$ of categories) (Table 3). In 22 of these categories (44\%), the negative correlation was significant $(p<0.05)$. 'Juices, nectars and fruit drinks' showed the strongest negative correlation $(-0.9, p<0.0001)$ while 'Croutons,' 'Quark, fresh cheese and fresh dairy desserts,' 'Plant-based beverages,' 'Measurable combination dishes', 'Not measurable combination dishes' and 'Major main entree with sauce' also showed a significant negative correlations ranging from -0.4 to $-0.6(p<0.001)$.

\section{Discussion}

This study demonstrates that 35\% of Canadian food products had manufacturer stated serving sizes that were lower than the Schedule $M$ reference amount. While many products fell within the CFIA recommended serving size ranges (which are quite large), the majority $(70 \%)$ were within the lower half of the range. Furthermore, in the majority of food categories, products with a smaller manufacturer stated serving size tended to have a higher calorie density. Therefore, the lack of regulated serving sizes on the NFt on packaged foods in Canada has led to a tendency for food manufacturers to state smaller serving sizes and consequently display lower calorie levels, particularly in high calorie density foods. Collectively, these results suggest that there is an urgent need to regulate and standardize the NFt serving sizes, as the current unregulated system has led to a large proportion of food products with a higher calorie density to report smaller serving sizes, which can be misleading to consumers.

These findings are concerning because it has been shown that only knowledgeable consumers will be motivated to spend time analyzing nutrition information accurately and few are able to do the calculations necessary to compare products with different serving sizes [13]. These results also illustrated the very wide range of serving sizes (some as high as ten-fold) within categories, used by manufacturers in Canada. Health Canada consumer research has shown that consumers find it difficult to compare products, particularly when different serving sizes are used on the Nft [13]; thus consumers may be falsely led to believe that they are consuming fewer calories, when in fact, they are simply eating less food. Data illustrate that the current non-standardized serving size system in Canada is confusing and can lead to dramatic underestimation of calorie intakes [7, 17]. Additionally, this is worrisome, because research has highlighted that certain consumers, such as those who are sensitive to potentially negative nutrients (such as calories), as well as those with less knowledge of nutrition, are likely to be most susceptible to serving size manipulations [18].

This study also illustrates the need to update the serving size recommendations and ranges outlined in Schedule M, to be more in line with the serving size recommendations in Canada's Food Guide. For example, in the 'juices, nectars and fruit drinks' category, most of the product's serving sizes were in agreement with the reference amount, yet greater than $84 \%$ of products exceeded the recommended serving size in CFG. This finding illustrates the disparities between the serving sizes recommended in regulatory documents versus consumer education tools for healthy eating. Therefore, while schedule $\mathrm{M}$ and the CFIA make their recommendations based on what is typically consumed, this may not reflect what is recommended in Canada's Food Guide. Using the amount typically consumed, rather than the recommended serving sizes, as the criteria for labelling, may in fact, promote increased serving sizes and food intakes and contribute to the increasing rate of obesity in Canada. 
Table 2 Comparison between the median calories currently listed on the Nutrition Facts Table (NFT) and the calories per reference amount

\begin{tabular}{|c|c|c|c|c|c|c|}
\hline Food group & Number & $\begin{array}{l}\text { Median Calories (kcal)/ } \\
\text { manufacturer stated } \\
\text { serving size on NFT (g) }\end{array}$ & $\begin{array}{l}\text { Median Calories (kcal)/ } \\
\text { reference amount }(\mathrm{g})\end{array}$ & $p^{*}$ & $\begin{array}{l}\text { Minimum calories (kcal)/ } \\
\text { serving size on NFT+ }(\mathrm{g})\end{array}$ & $\begin{array}{l}\text { Maximum calories }(\mathrm{kcal}) / \\
\text { serving size on } \mathrm{NFT}^{\mathrm{a}}(\mathrm{g})\end{array}$ \\
\hline \multicolumn{7}{|l|}{ Bakery Products } \\
\hline 1. Bread & 183 & 130 & 127 & 0.011 & 60 & 230 \\
\hline $\begin{array}{l}\text { 2. Bagels, tea biscuits, } \\
\text { scones etc. }\end{array}$ & 227 & 150 & 147 & 0.001 & 40 & 350 \\
\hline $\begin{array}{l}\text { 7. Coffee cakes, doughnuts, } \\
\text { danishes etc. }\end{array}$ & 89 & 200 & 215 & 0.913 & 60 & 520 \\
\hline 8. Cookies, graham wafers & 294 & 140 & 141 & 0.999 & 30 & 250 \\
\hline $\begin{array}{l}\text { 9. Crackers, hard bread } \\
\text { sticks etc. }\end{array}$ & 238 & 90 & 90 & na & 60 & 247 \\
\hline 14. Croutons & 53 & 35 & 30 & 0.001 & 25 & 110 \\
\hline $\begin{array}{l}\text { 15. French toast, pancakes, } \\
\text { and waffles }\end{array}$ & 93 & 140 & 167 & $0.001^{\ddagger}$ & 90 & 230 \\
\hline $\begin{array}{l}\text { 17. Grain-based bars with } \\
\text { filling and coating }\end{array}$ & 85 & 110 & 123 & 0.215 & 90 & 230 \\
\hline $\begin{array}{l}\text { 18. Rice cakes and corn } \\
\text { cakes }\end{array}$ & 62 & 60 & 64 & $0.028^{\ddagger}$ & 30 & 230 \\
\hline $\begin{array}{l}\text { 19. Pies, tarts, cobblers, } \\
\text { turnovers }\end{array}$ & 94 & 305 & 321 & $0.001^{\neq}$ & 80 & 430 \\
\hline \multicolumn{7}{|l|}{ Cereals and Other Grain Products } \\
\hline 28. Hot breakfast cereals & 57 & 150 & 155 & 0.127 & 90 & 210 \\
\hline $\begin{array}{l}\text { 30. Breakfast cereals } \\
\text { without fruit or nuts }\end{array}$ & 85 & 120 & 116 & 0.607 & 80 & 130 \\
\hline $\begin{array}{l}\text { 31. Breakfast cereals } \\
\text { with fruit and nuts }\end{array}$ & 145 & 210 & 214 & $0.022^{\ddagger}$ & 90 & 270 \\
\hline $\begin{array}{l}\text { 34. Grains, such as rice } \\
\text { or barley }\end{array}$ & 85 & 160 & 160 & 0.349 & 110 & 360 \\
\hline 35. Pastas without sauce & 383 & 300 & 302 & $0.007^{\ddagger}$ & 110 & 342 \\
\hline \multicolumn{7}{|l|}{ Dairy Products and Substitutes } \\
\hline 39. Cheese & 380 & 90 & 100 & $0.001^{\ddagger}$ & 20 & 190 \\
\hline $\begin{array}{l}\text { 43. Quark, fresh cheese } \\
\text { and fresh dairy desserts }\end{array}$ & 63 & 90 & 286 & $0.001^{\neq}$ & 60 & 190 \\
\hline 49. Plant-based beverages & 138 & 120 & 130 & $0.001^{\ddagger}$ & 30 & 230 \\
\hline 52. Yogurt & 95 & 100 & 140 & $0.001^{\neq}$ & 35 & 260 \\
\hline \multicolumn{7}{|l|}{ Desserts } \\
\hline $\begin{array}{l}\text { 53. Ice cream, ice milk, } \\
\text { frozen yogurt, sherbet }\end{array}$ & 282 & 140 & 140 & na & 60 & 340 \\
\hline 54. Dairy desserts, frozen & 97 & 180 & 250 & 0.001 & 40 & 360 \\
\hline \multicolumn{7}{|l|}{ Fats and Oils } \\
\hline $\begin{array}{l}\text { 64. Butter, margarine, } \\
\text { shortening, lard }\end{array}$ & 91 & 70 & 70 & na & 25 & 90 \\
\hline 65. Vegetable oil & 105 & 80 & 80 & $0.001^{\S}$ & 80 & 130 \\
\hline 67. Dressings for salad & 227 & 45 & 90 & $0.001^{\neq}$ & 10 & 160 \\
\hline \multicolumn{7}{|l|}{ Marine and Fresh Water Animals } \\
\hline $\begin{array}{l}\text { 72. Marine and fresh } \\
\text { water animals }\end{array}$ & 132 & 170 & 223 & $0.001^{\neq}$ & 65 & 540 \\
\hline $\begin{array}{l}\text { 73. Marine and fresh water } \\
\text { animals, canned }\end{array}$ & 116 & 90 & 71 & 0.001 & 25 & 240 \\
\hline
\end{tabular}


Table 2 Comparison between the median calories currently listed on the Nutrition Facts Table (NFT) and the calories per reference amount (Continued)

Fruits and Fruit Juices

\begin{tabular}{|c|c|c|c|c|c|c|}
\hline $\begin{array}{l}\text { 75. Fruit, fresh, canned } \\
\text { or frozen }\end{array}$ & 167 & 80 & 91 & $0.001^{\ddagger}$ & 30 & 220 \\
\hline 77. Dried fruit & 69 & 120 & 122 & 0.831 & 40 & 270 \\
\hline $\begin{array}{l}\text { 83. Juices, nectars and } \\
\text { fruit drinks }\end{array}$ & 553 & 120 & 125 & $0.001^{\ddagger}$ & 10 & 200 \\
\hline umes & & & & & & \\
\hline 86. Beans, peas and lentils & 78 & 340 & 350 & $0.001^{\ddagger}$ & 35 & 20 \\
\hline
\end{tabular}

Meat, Poultry, Their Products and Substitutes

\begin{tabular}{|c|c|c|c|c|c|c|}
\hline 90. Luncheon meats & 107 & 60 & 61 & $0.001^{\ddagger}$ & 30 & 170 \\
\hline 91. Sausages & 102 & 150 & 142 & 0.03 & 40 & 370 \\
\hline $\begin{array}{l}\text { 93. Patties, cutlettes, } \\
\text { chopettes etc. }\end{array}$ & 103 & 230 & 211 & 0.001 & 70 & 550 \\
\hline $\begin{array}{l}\text { 96. Meat and poultry } \\
\text { with sauce }\end{array}$ & 106 & 190 & 252 & $0.001^{\ddagger}$ & 90 & 410 \\
\hline \multicolumn{7}{|l|}{ Miscellaneous category } \\
\hline $\begin{array}{l}\text { 99. Bread crumbs and } \\
\text { batter mixes }\end{array}$ & 151 & 150 & 118 & 0.001 & 30 & 350 \\
\hline \multicolumn{7}{|l|}{ Combination Dishes } \\
\hline 107. Measurable & 366 & 275 & 284 & 0.957 & 110 & 700 \\
\hline 108. Not measurable & 304 & 290 & 309 & 0.907 & 80 & 660 \\
\hline 109. Hor d'oeuvres & 104 & 155 & 124 & 0.055 & 70 & 452 \\
\hline
\end{tabular}

Nuts and Seeds

110. Nuts and seeds 67

Sauces, Dips, Gravies and Condiments

\begin{tabular}{|c|c|c|c|c|c|c|}
\hline 120. Sauces for dipping & 117 & 60 & 60 & na & 10 & 170 \\
\hline 121. Dips & 92 & 60 & 63 & 0.907 & 15 & 170 \\
\hline $\begin{array}{l}\text { 122. Major main entree } \\
\text { sauce }\end{array}$ & 145 & 70 & 70 & $0.001^{\S}$ & 20 & 270 \\
\hline $\begin{array}{l}\text { 123. Minor main entree } \\
\text { sauce }\end{array}$ & 102 & 20 & 25 & $0.001^{\ddagger}$ & 10 & 310 \\
\hline 124. Major condiments & 100 & 20 & 20 & na & 5 & 70 \\
\hline 125. Minor condiments & 48 & 5 & 5 & 0.248 & 0 & 80 \\
\hline \multicolumn{7}{|l|}{ nnacks } \\
\hline $\begin{array}{l}\text { 126. Chips, pretzels, } \\
\text { popcorn, extruded } \\
\text { snacks }\end{array}$ & 375 & 240 & 250 & $0.001^{\neq}$ & 40 & 330 \\
\hline $\begin{array}{l}\text { 127. Nuts or seeds for } \\
\text { use as snacks }\end{array}$ & 88 & 280 & 290 & $0.021^{\ddagger}$ & 160 & 440 \\
\hline \multicolumn{7}{|l|}{ Sugars and Sweets } \\
\hline $\begin{array}{l}\text { 137. Jams, jellies, } \\
\text { marmalades etc. }\end{array}$ & 145 & 50 & 50 & 0.479 & 5 & 80 \\
\hline 141. Syrups & 50 & 120 & 220 & $0.001^{\ddagger}$ & 30 & 8 \\
\hline
\end{tabular}

Vegetables

150. Pickles 
Table 3 Correlation between serving size and calorie density in each Schedule $\mathrm{M}^{\mathrm{a}}$ food category

\begin{tabular}{|c|c|c|c|}
\hline Food group & Number & Pearson Correlation - $r$ & $p$ \\
\hline \multicolumn{4}{|l|}{ Bakery Products } \\
\hline 1. Bread & 183 & -0.3493 & 0 \\
\hline 2. Bagels, tea biscuits, scones etc. & 227 & 0.006 & 0.0001 \\
\hline 7. Coffee cakes, doughnuts, danishes etc. & 89 & -0.3107 & 0.003 \\
\hline 8. Cookies, graham wafers & 294 & -0.0972 & 0.0961 \\
\hline 9. Crackers, hard bread sticks etc. & 238 & -0.2227 & 0.0005 \\
\hline 14. Croutons & 53 & -0.6452 & 0 \\
\hline 15. French toast, pancakes, and waffles & 93 & -0.2151 & 0.0384 \\
\hline 17. Grain-based bars with filling and coating & 85 & 0.1998 & 0.0667 \\
\hline 18. Rice cakes and corn cakes & 62 & 0.5732 & 0 \\
\hline 19. Pies, tarts, cobblers, turnovers & 94 & -0.3318 & 0.0011 \\
\hline \multicolumn{4}{|l|}{ Cereals and Other Grain Products } \\
\hline 28. Hot breakfast cereals & 57 & 0.2337 & 0.0802 \\
\hline 30. Breakfast cereals without fruit or nuts & 85 & -0.3751 & 0.0004 \\
\hline 31. Breakfast cereals with fruit and nuts & 145 & 0.0097 & 0.9079 \\
\hline 34. Grains, such as rice or barley & 85 & 0.2446 & 0.0241 \\
\hline 35. Pastas without sauce & 383 & -0.008 & 0.8757 \\
\hline \multicolumn{4}{|l|}{ Dairy Products and Substitutes } \\
\hline 39. Cheese & 380 & 0.2066 & 0.00005 \\
\hline 43. Quark, fresh cheese and fresh dairy desserts & 63 & -0.4323 & 0.0004 \\
\hline 49. Plant-based beverages & 138 & -0.4618 & 0 \\
\hline 52. Yogurt & 95 & -0.0726 & 0.4845 \\
\hline \multicolumn{4}{|l|}{ Desserts } \\
\hline 53. Ice cream, ice milk, frozen yogurt, sherbet & 282 & 0.2197 & 0.0002 \\
\hline 54. Dairy desserts, frozen & 97 & 0.5856 & 0 \\
\hline \multicolumn{4}{|l|}{ Fats and Oils } \\
\hline 64. Butter, margarine, shortening, lard & 91 & -0.202 & 0.0548 \\
\hline 65. Vegetable oil & 105 & 0.2112 & 0.0306 \\
\hline 67. Dressings for salad & 227 & 0.0552 & 0.408 \\
\hline \multicolumn{4}{|l|}{ Marine and Fresh Water Animals } \\
\hline 72. Marine and fresh water animals & 132 & -0.353 & 0.00003 \\
\hline 73. Marine and fresh water animals, canned & 116 & 0.2288 & 0.0135 \\
\hline \multicolumn{4}{|l|}{ Fruits and Fruit Juices } \\
\hline 75. Fruit, fresh, canned or frozen & 167 & -0.2265 & 0.0032 \\
\hline 77. Dried fruit & 69 & -0.2073 & 0.0874 \\
\hline 83. Juices, nectars and fruit drinks & 553 & -0.9073 & 0 \\
\hline \multicolumn{4}{|l|}{ Legumes } \\
\hline 86. Beans, peas and lentils & 78 & -0.227 & 0.0457 \\
\hline \multicolumn{4}{|l|}{ Meat, Poultry, Their Products and Substitutes } \\
\hline 90. Luncheon meats & 107 & 0.1014 & 0.2989 \\
\hline 91. Sausages & 102 & -0.0376 & 0.0014 \\
\hline 93. Patties, cutlettes, chopettes etc. & 103 & 0.1431 & 0.1493 \\
\hline 96. Meat and poultry with sauce & 106 & -0.3741 & 0.00008 \\
\hline
\end{tabular}


Table 3 Correlation between serving size and calorie density in each Schedule $\mathrm{M}^{\mathrm{a}}$ food category (Continued)

\begin{tabular}{|c|c|c|c|}
\hline \multicolumn{4}{|l|}{ Miscellaneous category } \\
\hline 99. Bread crumbs and batter mixes & 151 & -0.2137 & 0.0084 \\
\hline \multicolumn{4}{|l|}{ Combination Dishes } \\
\hline 107. Measurable & 366 & -0.5304 & 0 \\
\hline 108. Not measurable & 304 & -0.6052 & 0 \\
\hline 109. Hor d'oeuvres & 104 & -0.2401 & 0.0141 \\
\hline \multicolumn{4}{|l|}{ Nuts and Seeds } \\
\hline 110. Nuts and seeds & 67 & -0.2491 & 0.0421 \\
\hline \multicolumn{4}{|l|}{ Sauces, Dips, Gravies and Condiments } \\
\hline 120. Sauces for dipping & 117 & -0.2977 & 0.0011 \\
\hline 121. Dips & 92 & -0.0984 & 0.3506 \\
\hline 122. Major main entree sauce & 145 & -0.4883 & 0 \\
\hline 123. Minor main entree sauce & 102 & 0.2153 & 0.0298 \\
\hline 124. Major condiments & 100 & 0.2593 & 0.0092 \\
\hline 125. Minor condiments & 48 & 0.1166 & 0.43 \\
\hline \multicolumn{4}{|l|}{ Snacks } \\
\hline 126. Chips, pretzels, popcorn, extruded snacks & 375 & 0.5575 & 0 \\
\hline 127. Nuts or seeds for use as snacks & 88 & -0.1716 & 0.1099 \\
\hline \multicolumn{4}{|l|}{ Sugars and Sweets } \\
\hline 137. Jams, jellies, marmalades etc. & 145 & 0.0318 & 0.7042 \\
\hline 141. syrups & 50 & -0.0321 & 0.8323 \\
\hline \multicolumn{4}{|l|}{ Vegetables } \\
\hline 150. Pickles & 54 & -0.1669 & 0.2278 \\
\hline
\end{tabular}

50 of the 153 categories in schedule $\mathrm{M}$ had greater than 50 foods and thus were included in the analysis

${ }^{a}$ Schedule $M$ is a component of the Food and Drug Regulations (B.01.001) which includes reference amounts and recommended serving sizes for the Nutrition Facts table on packaged food products. These references are voluntary and are only mandatory when manufacturers are aiming to meet the compositional criteria for nutrient content claims and health claims

Standardizing serving sizes as well as aligning them with recommended servings in Canada's Food Guide, is only one potential solution to this problem. For example, in the food regulations set out by the Food Standards Australia New Zealand, products are required to present nutrient levels both per serving size and per $100 \mathrm{~g} / \mathrm{mL}$ using a dualcolumn system, thus enabling comparisons amongst products irrespective of their serving sizes [17]. The EU similarly avoids the need to regulate serving sizes by reporting nutrient levels per $100 \mathrm{~g}$ [19]. Interestingly, the "Labelling Logic Review" in Australia, recommended that serving sizes be removed from the Nutrition Information Panel (NIP), aiming to simplify requirements for the mandatory NIP and reduce the regulatory burden on industry [20]. However, no further work has been be undertaken on this recommendation due to the perceived lack of benefit [21]. The Public Health Association of Australia (PHAA) stated that removing the serving size column would not solve the problem of consumer confusion and recommended that the only approach to dealing with the inconsistency in serving sizes is to mandate serving sizes within food categories, as is being currently implemented in Canada [15].
Furthermore, the more fundamental question is, what types of nutrition label information actually assists consumers to make healthier food choices? For example, Roberto and Khandpur had suggested package design might also help educate consumers about appropriate serving sizes by having markers on the outside of food packaging that denote serving size amounts; or having clear indicators of pre-portioned servings in the package design [22]. Not to mention, effective consumer education is an essential co-requirement to enable consumers to understand the valuable information on the NFt.

This study evaluated a large number of foods from a wide variety of food categories. Limitations include the fact that Schedule $M$ serving sizes were not available for a number of sub-categories. In addition, our study only investigated calories, and did not analyze other nutrient levels in relation to the manufacturer stated serving size. Hunter et al. noted that discrepancies in serving-size are often attributed to the use of food products for different purposes [23], thus a higher serving size could be advantageous if the manufacturer inflates the content of a healthy nutrient. Our study did not investigate other factors that could motivate serving size manipulations. 


\section{Conclusion}

These findings provide data to support the benefits of standardized serving sizes on Nutrition Facts tables. The study also reinforces findings from previous research studies which suggest that in jurisdictions where serving sizes are not standardized, manufacturers can alter consumer perceptions of the healthfulness of a product-particularly its calorie level-simply by decreasing the serving size, without changing the overall nutritional quality of the product, as illustrated by the negative correlation between serving size and calorie density. Therefore, in light of the obesity and diet-related chronic disease epidemic, further research is required to inform policies to help consumers make sense of the NFt amidst a confusing food environment. Nutrition labelling policies that assist consumers to make informed food selection choices are one step towards addressing this pressing public health issue.

\section{Additional file}

Additional file 1: List of food categories with reference amount, serving size and FLIP data characteristics. This table outlines the food categories included in the paper along with the Schedule $\mathrm{M}$ reference amounts, CFIA suggested serving sizes and the number of products in the FLIP database that corresponded to each category. (DOCX $23 \mathrm{~kb}$ )

\section{Abbreviations}

CFG: Canada's Food Guide; CFIA: Canadian Food Inspection Agency; EU: European Union; FLIP: Food Label Information Program; FDA: Food and Drug Administration; FDR: Food and Drug Regulations; NIP: Nutrition Information Panel; NFt: Nutrition Facts table; PHAA: Public Health Association of Australia; RACC: Reference Amount Customarily Consumed; UK: United Kingdom

\section{Acknowledgements}

The authors thank all members from the L'Abbé Lab who contributed to the creation of the FLIP 2010 database.

\section{Funding}

This work was supported by the Dr. Lorus J Milne and Dr. Margery J Milne Award (JC); Canadian Institutes of Health Research, Vanier Canada Graduate Scholarship (MS), Strategic Training Program in Public Health Policy (MS); Cancer Care Ontario/CIHR Training Grant in Population Intervention for Chronic Disease Prevention: A Pan-Canadian Program (Grant No. 538932)(MS); McHenry Unrestricted Research Grant from the University of Toronto (ML). The funding agencies were not involved whatsoever in the study design, data collection, analysis/interpretation or writing of the manuscript.

\section{Availability of data and materials}

The datasets analysed during the current study available from the corresponding author on reasonable request.

\section{Authors' contributions}

Formulation of the research question (JC, MS, ML); study design (JC, MS); data collection (JC); data analysis (JC, MS); data interpretation (JC, MS, ML); drafting of the manuscript (JC, MS); critical review of the manuscript (JC, MS, $\mathrm{ML}$ ). All authors have read and approved the final version of the manuscript.

\section{Competing interests}

The authors declare that they have no competing interests.

\section{Consent for publication}

Not applicable.
Ethics approval and consent to participate

Ethics approval was not required for this study as it does not involve human subjects and is based solely on food package data

\section{Publisher's Note}

Springer Nature remains neutral with regard to jurisdictional claims in published maps and institutional affiliations.

\section{Author details}

${ }^{1}$ Faculty of Medicine, Department of Nutritional Sciences, University of Toronto, Fitzgerald Building, 150 College St., Rm 315, Toronto, ON M1S 3E2, Canada. ${ }^{2}$ Prenetics Ltd., Prenetics Ltd. 7/F, Prosperity Millennia Plaza, 663 King's Rd, Quarry Bay, Hong Kong, China.

Received: 15 August 2016 Accepted: 2 May 2017

Published online: 08 May 2017

\section{References}

1. Public Health Agency of Canada-Canadian Institute for Health Information, Obesity in Canada - A joint report from the Public Health Agency of Canada and the Canadian Institute for Health Information. 2011.

2. Ledikwe $\mathrm{JH}$, Ello-Martin JA, Rolls BJ. Portion sizes and the obesity epidemic. J Nutr. 2005;135(4):905-9.

3. Canadian Food Inspection Agency. Food Labelling for Industry - Nutrition Labelling. 2015 July 2015 [cited 24 2015]; Available from: http://www. inspection.gc.ca/food/labelling/food-labelling-for-industry/nutritionlabelling/eng/1386881685057/1386881685870.

4. U.S. Food and Drug Administration. Guidance for Industry: Letter Regarding Point of Purchase Food Labeling. 20142009 [cited March 30]; Available from: http://www.fda.gov/Food/GuidanceRegulation/ GuidanceDocumentsRegulatory Information/LabelingNutrition/ucm187208.htm.

5. European Commission. New EU law on food information to consumers. 20172014 [cited March 3]; Available from: http://ec.europa.eu/food/safety/ labelling nutrition/labelling_legislation en.

6. Food Standards Australia New Zealand. Nutrition information panels. 2017 2015 [cited March 5]; Available from: http://www.foodstandards.gov.au/ consumer/labelling/panels/Pages/default.aspx.

7. Bryant R, Dundes L. Portion Distorition: A Study of College Students. The Journal of Consumer Affairs. 2005;39(2):399-408.

8. Mohr GLDR, Janiszewski C. The Effect of Marketer-Suggested Serving Size on Consumer Responses: The Unintended Consequences of Consumer Attention to Calorie Information. J Mark. 2012;76(1):59-75.

9. Vanderlee $L$, et al. Consumer understanding of calorie amounts and serving size: implications for nutritional labelling. Can J Public Health. 2012;103(5): e327-31.

10. Health Canada. Canada's Food and Drugs Act \& Regulations. 20172016 [cited March 3]; Available from: http://www.hc-sc.gc.ca/fn-an/legislation/ acts-lois/act-loi_reg-eng.php.

11. Canada Food Inspection Agency. Frequently Asked Questions: Consumer Packaging and Labelling Regulations. 20172015 [cited March 3]; Available from: http://www.inspection.gc.ca/about-the-cfia/acts-and-regulations/faqconsumer-packaging-and-labelling-regulations/eng/1426692873531/ 1426692889910

12. Canadian Food Inspection Agency. Information within the Nutrition Facts Table - Reference Amounts. 2015 [cited 201520 July]; Available from: http:// www.inspection.gc.ca/food/labelling/food-labelling-for-industry/nutritionlabelling/information-within-the-nutrition-facts-table/eng/1389198568400/ 1389198597278 ? chap $=5$.

13. Health Canada. Nutrition Labelling and Claims Regulations-Frequently Asked Questions. 2003 [cited October 12 2011]; Available from: http://www.hc-sc gc.ca/fn-an/label-etiquet/nutrition/reg/regulations-reglements-faqs-eng.php.

14. US. Food and Drug Administration. Guidance for Industry: A Food Labelling Guide. 2015 July 2013 [cited 24 2015]; Available from: http://www.fda.gov/ Food/GuidanceRegulation/GuidanceDocumentsRegulatoryInformation/ LabelingNutrition/ucm2006828.htm.

15. Government of Canada. Food labelling changes. 20172016 [cited March 5]; Available from: http://www.healthycanadians.gc.ca/eating-nutrition/labeletiquetage/changes-modifications-eng.php. 
16. Schermel A, et al. Nutrition marketing on processed food packages in Canada: 2010 food label information program. Appl Physiol Nutr Metab. 2013;38(6):666-72.

17. Health Canada. Consulting Canadians to Modernize and Improve Food Labels: What We Heard. 20162014 [cited 18 January]; Available from: http:// www.hc-sc.gc.ca/fn-an/label-etiquet/modernize-report-moderniser-rapporteng.php.

18. Rizk MT. Treat, Teresa a, Sensitivity to portion size of unhealthy foods. Food Qual Prefer. 2015:45:121-31.

19. Regulation (EU) No 1169/2011 of the European Parliament and of the Council of 25 October 2011 on the provision of food information to consumers. 20152011 [cited July 24]; Available from: http://eur-lex.europa. eu/LexUriServ/LexUriServ.do?uri=OJ:L:2011:304:0018:0063:EN:PDF.

20. Public Health Association of Australia. Submission to Consultatioin PaperLabelling Review Recommendation 17: Per serving declarations in the nutrition information panel. 20172015 [cited March 3]; Available from https://www.phaa.net.au/documents/item/372

21. Food Standards Australia New Zealand. Labelling review recommendation 17. 20172015 [cited March 3]; Available from: https:/www.foodstandards.gov.au/ consumer/labelling/review/Pages/labelling-review-recommendation-17.aspx.

22. Roberto CA, Khandpur N. Improving the design of nutrition labels to promote healthier food choices and reasonable portion sizes. Int J Obes. 2014;38(Suppl 1):S25-33.

23. Hunter B. Serving size confusion. Consumers' Research Magazine. 2002;85(2): 8-10.

\section{Submit your next manuscript to BioMed Central and we will help you at every step:}

- We accept pre-submission inquiries

- Our selector tool helps you to find the most relevant journal

- We provide round the clock customer support

- Convenient online submission

- Thorough peer review

- Inclusion in PubMed and all major indexing services

- Maximum visibility for your research

Submit your manuscript at www.biomedcentral.com/submit

C) Biomed Central 